\title{
The nighttime ionospheric response and occurrence of equatorial plasma irregularities during geomagnetic storms: a case study
}

\author{
Xin Wan ${ }^{1}$, Chao Xiong ${ }^{2 *}$, Shunzu Gao ${ }^{2}$, Fuqing Huang ${ }^{3,4}$, Yiwen Liư ${ }^{5}$ Ercha Aa ${ }^{6}$, Fan Yin ${ }^{2}$ and Hongtao Cai ${ }^{2}$
}

\begin{abstract}
Recent studies revealed that the long-lasting daytime ionospheric enhancements of Total Electron Content (TEC) were sometimes observed in the Asian sector during the recovery phase of geomagnetic storms (e.g., Lei (J Geophys Res Space Phys 123: 3217-3232, 2018), Li (J Geophys Res Space Phys 125: e2020JA028238, 2020). However, they focused only on the dayside ionosphere, and no dedicated studies have been performed to investigate the nighttime ionospheric behavior during such kinds of storm recovery phases. In this study, we focused on two geomagnetic storms that happened on 7-8 September 2017 and 25-26 August 2018, which showed the prominent daytime TEC enhancements in the Asian sector during their recovery phases, to explore the nighttime large-scale ionospheric responses as well as the small-scale Equatorial Plasma Irregularities (EPIs). It is found that during the September 2017 storm recovery phase, the nighttime ionosphere in the American sector is largely depressed, which is similar to the daytime ionospheric response in the same longitude sector; while in the Asian sector, only a small TEC increase is observed at nighttime, which is much weaker than the prominent daytime TEC enhancement in this longitude sector. During the recovery phase of the August 2018 storm, a slight TEC increase is observed on the night side at all longitudes, which is also weaker than the prominent daytime TEC enhancement. For the small-scale EPIs, they are enhanced and extended to higher latitudes during the main phase of both storms. However, during the recovery phases of the first storm, the EPIs are largely enhanced and suppressed in the Asian and American sectors, respectively, while no prominent nighttime EPIs are observed during the second storm recovery phase. The clear northsouth asymmetry of equatorial ionization anomaly crests during the second storm should be responsible for the suppression of EPIs during this storm. In addition, our results also suggest that the dusk side ionospheric response could be affected by the daytime ionospheric plasma density/TEC variations during the recovery phase of geomagnetic storms, which further modulates the vertical plasma drift and plasma gradient. As a result, the growth rate of post-sunset EPIs will be enhanced or inhibited.
\end{abstract}

Keywords: Geomagneitc storm, Storm recovery phase, lonospheric response, Equatorial plasma irregularity, Longitudinal variations

\footnotetext{
*Correspondence: xiongchao@whu.edu.cn

2 Department of Space Physics, Electronic Information School, Wuhan University, Wuhan 430072, China

Full list of author information is available at the end of the article
}

\begin{abstract}
Introduction
During geomagnetic storms, large amounts of energy and momentum from the solar wind and magnetosphere are deposited into the Earth's upper atmosphere and ionosphere, via increased particle precipitation and Joule heating. The enhanced electric fields at high latitudes
\end{abstract}

Springer Open

(c) The Author(s) 2021. Open Access This article is licensed under a Creative Commons Attribution 4.0 International License, which permits use, sharing, adaptation, distribution and reproduction in any medium or format, as long as you give appropriate credit to the original author(s) and the source, provide a link to the Creative Commons licence, and indicate if changes were made. The images or other third party material in this article are included in the article's Creative Commons licence, unless indicated otherwise in a credit line to the material. If material is not included in the article's Creative Commons licence and your intended use is not permitted by statutory regulation or exceeds the permitted use, you will need to obtain permission directly from the copyright holder. To view a copy of this licence, visit http://creativecommons.org/licenses/by/4.0/. 
under southward Interplanetary Magnetic Field (IMF) conditions can penetrate almost instantaneously to the equatorial region, known as the Prompt Penetration Electric Fields (PPEFs) (e.g., Kikuchi et al., 1996; Nishida, 1968). In the meanwhile, enhanced Joule heating at auroral latitudes causes the expansion of the neutral atmosphere, which further drives equatorward neutral wind and launches traveling atmospheric/ionospheric disturbances (e.g., Hocke \& Schlegel, 1996; Richmond \& Matsushita, 1975). The equatorward winds turn westward at middle and low latitudes (e.g., Xiong et al., 2015) due to the Coriolis force and further generate Disturbance Dynamo Electric Fields (DDEFs) (e.g., Blanc \& Richmond, 1980; Scherliess \& Fejer, 1997).

The geomagnetic storms usually cause global disturbances of the ionosphere, but due to the complex coupling of Earth's magnetosphere-ionosphere-thermosphere system, the ionospheric disturbances perform quite differently from storm to storm. Despite the differences, in a general manner the geomagnetic storm surges tend to develop firstly in the nighttime sector where the neutral winds are preferably equatorward (Prölss, 1993; Fuller-Rowell et al., 1997), therefore larger ionospheric responses are thus more often observed at the longitudes on the nightside where the high-latitude energy injection happens. Considering the seasonal effect, a positive ionospheric storm is often found in the winter hemisphere, while the negative response prefers to be observed in the summer hemisphere (e.g., Goncharenko et al., 2007; Prölss, 1995), though sometimes the summer-winter hemispheric asymmetry of ionospheric responses shows also altitudinal dependence (e.g., Astafyeva et al., 2015).

Recently, Pedatella (2016) pointed out one interesting question that whether the lower atmosphere activities can modulate the ionospheric responses to a geomagnetic storm, especially at the storm later stage when the solar wind and IMF disturbances start to recover. Pedatella and Liu (2018) used the Whole Atmosphere Community Climate Model eXtended (WACCM-X) to quantify the contribution of lower atmospheric variability to the ionospheric response during an idealized geomagnetic storm. Regardless of the day-to-day variability of the lower atmosphere, they found that the regional differences of ionospheric Total Electron Content (TEC) can reach $50 \%$. For the storm main phase on 7-8 September 2017, Lei et al. (2018) reported an interesting phenomenon that the daytime TEC in the Asian longitudinal sector exhibited a long-lasting enhancement in the storm recovery phase on 9-11 September 2017. They further suggested that such a daytime TEC enhancement was possibly related to the lower atmospheric forcing during the storm recovery phase. For the same storm event, Xiong et al. (2019) further found that the dayside ionosphere at low- and equatorial-latitudes exhibited prominent positive and negative responses in the Asian and American longitudinal sectors, respectively, which agrees very well with the Equatorial Electrojet (EEJ) variations observed with two ground-based magnetometers located at Huancayo in Peru and Davao in the Philippines. Similar long-lasting daytime TEC enhancements at low and equatorial latitudes were observed in another storm recovery phase on 27-30 August 2018 (Li et al., 2020), but the opposite ionospheric response in Asian and American sectors as reported by Xiong et al. (2019) was not observed.

Although the above-mentioned studies all suggest that the long-lasting daytime TEC enhancements during the storm recovery phase should be related to the lower atmospheric forcing, the direct evidence of enhanced tides or waves at lower atmospheric altitude was not provided. As pointed in the earlier studies, some of the lower atmospheric tides and waves can propagate upward to the $\mathrm{E}$ region and modulate the electric fields. Due to the high conductivity between the $\mathrm{E}$ and $\mathrm{F}$ regions at daytime caused by the wind dynamo, the tides and waves further map to the $\mathrm{F}$ region, causing longitudinal patterns of the topside ionosphere (e.g., England et al., 2010; Immel et al., 2006; Scherliess et al., 2008; Wan et al., 2010). In addition, the direct upward propagation of tides and waves can also contribute to the longitudinal variability of the thermosphere and topside ionosphere in night hours when the E region dynamo effect does no longer exist (e.g., Hagan et al., 2009; Häusler \& Lühr, 2009). Therefore, if the TEC enhancements in the storm recovery phase reported by Lei et al. (2018) and Xiong et al. (2019) are indeed related to the lower atmospheric tides and wave forcing, their influences on the topside ionosphere shall be effective not only in the dayside but also in the nightside.

Thus, the nighttime ionospheric behavior can potentially provide additional evidence of the neutral tide/ wave effects during geomagnetic storm recovery phases. In addition, the nighttime ionospheric disturbances should also affect the generation and development of nighttime small-scale structures at low and equatorial latitudes and the Equatorial Plasma Irregularities (EPIs, also named as the equatorial plasma bubble or equatorial spread F), which can severely impact the trans-ionospheric radio wave signals (e.g., Basu \& Basu, 1981; Xiong et al., 2016, 2018), and pose threats to the satellite navigation (e.g., Kintner et al., 2001). As the growth of EPIs is tightly related to the background state of the thermosphere and ionosphere (e.g., Sultan, 1996; Carter et al., 2014; Wan et al., 2019), the investigation of EPIs will help diagnose the impact of a geomagnetic storm on the 
ionosphere-thermosphere coupling, which in turn further advances our understanding of the day-to-day variability of EPIs.

In this study, we focus on the nighttime ionospheric response during the recovery phase of the storms in September 2017 and August 2018. An interesting question to be answered is if the nighttime ionosphere shows a similar response to the variations in the daytime when considering the lower atmospheric forcing on the topside ionosphere. In addition, we will check if the small-scale EPIs have the same longitudinal pattern as the daytime ionospheric responses during storm recovery phases. In the sections following, we firstly introduce the dataset and then give a brief overview of the geomagnetic storms that happened on 7-8 September 2017 and 25-26 August 2018. In Sect. 3 we show the TEC observations derived from a Global Navigation Satellite System (GNSS) network as well as the BeiDou Geostationary Orbit (GEO) satellites at two ground-based stations in the Asian sector. The small-scale EPIs are further derived from the TEC data of BeiDou GEO satellites as well as the F-region in situ electron density $(\mathrm{Ne})$ measurements with Swarm satellites. In Sect. 4 we discuss the previous studies. The main findings are summarized in Sect. 5.

\section{Dataset and approach}

\section{Ground-based TEC observations and in situ electron} density measurements from the Swarm satellites

For showing the ionospheric variations, the global TEC measurements provided by the Massachusetts Institute of Technology (MIT) are used in this study, which are freely accessible at the Madrigal database (e.g., Coster et al., 2003). In addition, the TEC values derived from BeiDou GEO satellites at one Asian station (SHEZ) are also used. One advantage of the TEC derived from BeiDou GEO satellites is that the radio wave paths between the GEO satellites and a ground receiver are almost fixed, leading to the stationary Ionospheric Pierce Points (IPPs). Therefore, it is very useful for continuously monitoring the small-scale ionospheric variations (e.g., Huang et al., 2017, 2018).

The Swarm constellation from the European Space Agency (ESA) is composed of three identical satellites that fly in near-polar orbits. In the final constellation, the lower pair, Swarm A and C, is flying side-by-side at an altitude of about $450 \mathrm{~km}$ with a longitudinal separation of $1.4^{\circ}$ (about $150 \mathrm{~km}$ ), while the third spacecraft, Swarm B, orbits the Earth at the altitude about $50 \mathrm{~km}$ higher than the former. For covering $24 \mathrm{~h}$ of Local Time (LT), Swarm A and C need about 133 days and Swarm B about 141 days. The in-situ Ne measurements used in this study are provided by the onboard Langmuir Probe at a sample rate of $2 \mathrm{~Hz}$. During the geomagnetic storm on 7-8 September 2017, for the night side orbits Swarm A and C flew in 22:15 LT, and Swarm B in 03:50 LT. During the geomagnetic storm on 25-26 August 2018, Swarm A and C flew in 02:30 LT, and Swarm B in 21:30 LT.

\section{Identify small-scale plasma irregularities from BeiDou GEO TEC and the in-situ Ne measurements of Swarm}

As the global TEC values provided by MIT have a time cadence of $5 \mathrm{~min}$, they are not suitable to show the smallscale plasma irregularities. Therefore, we used the BeiDou GEO TEC values which have a time cadence of $30 \mathrm{~s}$. For detecting the small-scale irregularities, a high-pass filter with a cut-off period of $50 \mathrm{~min}$ is applied to the TEC time series. Considering a typical east-west drift velocity of irregularities is about $100 \mathrm{~m} / \mathrm{s}$ (e.g., Yao \& Makela, 2007), the 50 min cut-off period corresponds to a zonal wavelength of about $300 \mathrm{~km}$.

For detecting the irregularities from the Swarm $\mathrm{Ne}$ measurements, a similar high-pass filter with a cutoff period of $40 \mathrm{~s}$ was applied to the $\mathrm{Ne}$ time series. Considering the velocity of Swarm satellites is about $7.5 \mathrm{~km} / \mathrm{s}$, the $40 \mathrm{~s}$ cutoff period corresponds to an along-track wavelength of about $300 \mathrm{~km}$, which is comparable to the irregularity wavelength of the BeiDou GEO derived TEC. To focus on the equatorial and low latitude region, for each orbit of Swarm we considered the data series only between $\pm 45^{\circ}$ Magnetic Latitude (MLAT), which was calculated by the Apex or Quasi-Dipole magnetic field model (Emmert et al., 2010). For the details about this approach, readers are referred to Xiong et al., (2010, 2016). Note that with the above-mentioned approaches, the plasma irregularities considered in this study are mainly with scale-size less than $300 \mathrm{~km}$.

\section{Results}

Overview on the geomagnetic disturbance conditions for the geomagnetic storms on 7-8 September 2017 and 25-26 August 2018

During 6-11 September 2017, dozens of M-class and four X-class flares were observed. In the meanwhile, several powerful interplanetary Coronal Mass Ejections (CME) caused severe near-Earth environment disturbances. Figure 1a shows the variations of solar wind velocity $\left(V_{S W}\right)$, three components of IMF in the Geocentric-Solar-Magnetospheric (GSM) coordinate, geomagnetic indices $S Y M-H$, and the 3-hr $K p$. Two abrupt increases in solar wind velocity were found shortly before 00:00 and around 23:00 Coordinated Universal Time (UTC) on 7 September, with the largest value exceeding $800 \mathrm{~km} / \mathrm{s}$. The data gap of $V_{S W}$ on 11 September is due to a solar energetic proton event as reported by Redmon et al. (2018). The IMF 
(a)

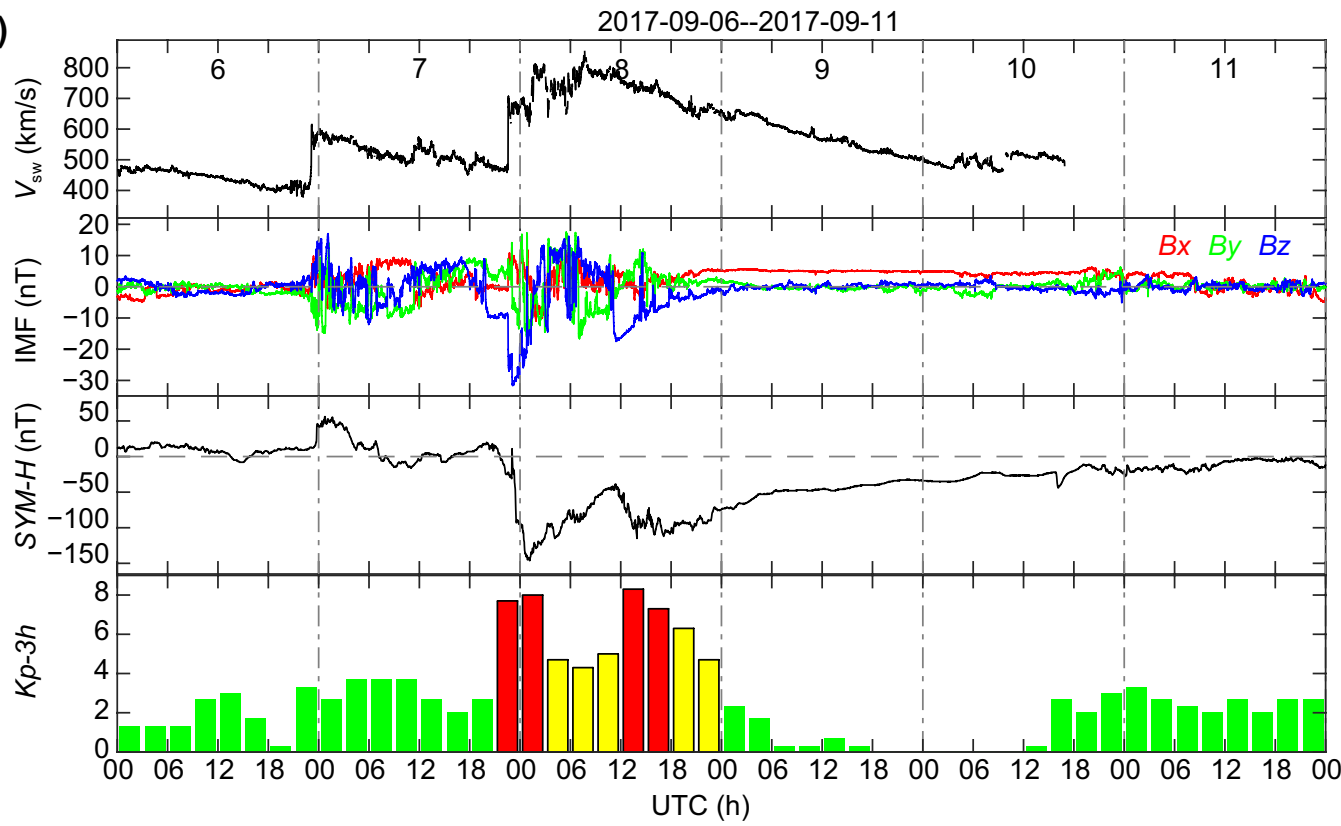

(b)

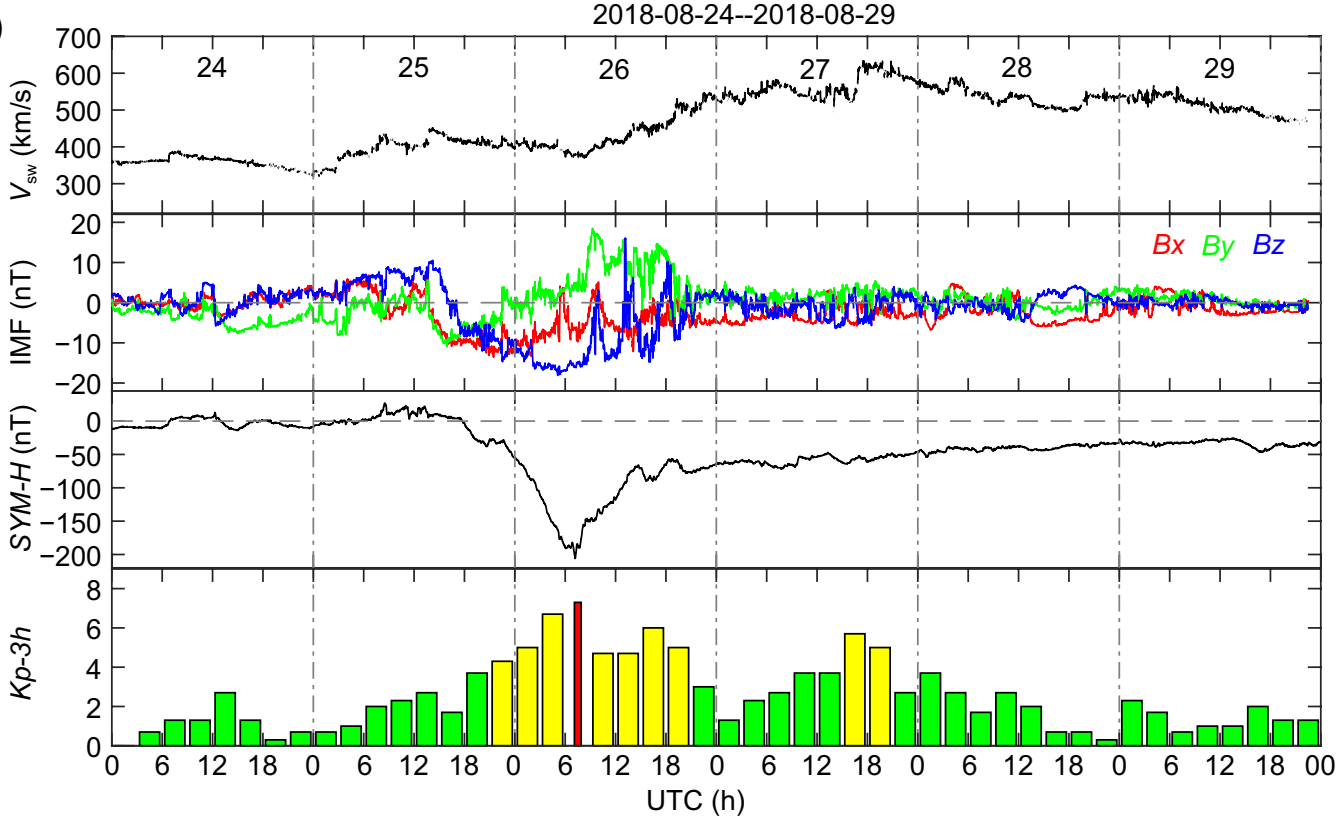

Fig. 1 The variations of solar wind velocity, IMF components, SYM-H index, and 3-h Kp index during the geomagnetic storm on a 6-11 September 2017 and b 24-29 August 2018

components show large fluctuations when the solar wind was dynamic, and the southward $B_{z}$ reached the minimum value of $-31 \mathrm{nT}$. A fast decrease of $S Y M-H$ was also seen around midnight of 7 September, with the first minimum reaching $-146 \mathrm{nT}$ and the second minimum reaching -115 nT. During the storm main phase, the $K p$ index reached over 7 . From 9 September, the solar wind velocity started to decrease, and the other geomagnetic indices started to recover, indicating that the quiet conditions during the recovery phase lasted for several days.

During 25-26 August 2018, there was also a CMEinduced magnetic storm. As shown in Fig. 1b, the solar wind velocity started to increase on 25 August. The 

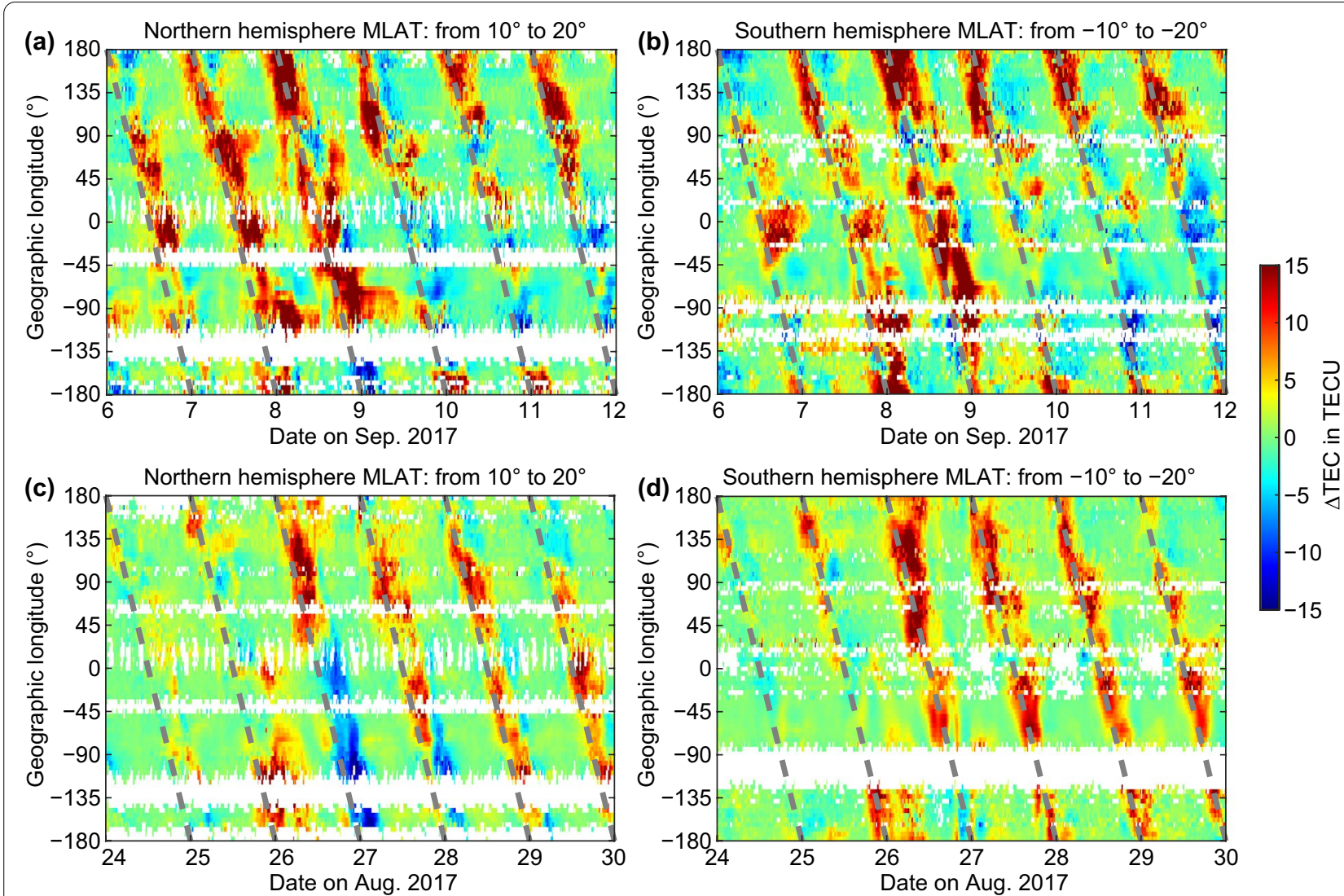

Fig. 2 The longitude versus UTC (in a time cadence of $15 \mathrm{~min}$ ) variations of ionospheric perturbation ( $\triangle T E C)$ for the (a and $\mathbf{c})$ northern $\left(10^{\circ}\right.$ to $20^{\circ}$ MLAT) and (b and $\mathbf{d})$ southern ( $-10^{\circ}$ to $-20^{\circ}$ MLAT) EIA crest regions during geomagnetic storms on (a and $\left.\mathbf{b}\right) 6-11$ September 2017 and (c and d) 24-29 August 2018. The gray dashed lines represent the local noon at different longitudes

three components of IMF were quite dynamic during the storm, the minimum value of $S Y M-H$ reached -174 $\mathrm{nT}$ at 7:00 UTC on 26 August 2018, and the maximum $K p$ index was over 7. Different from the first storm, the solar wind didn't reach its highest velocity in the storm main phase but kept increasing during the storm recovery phase with a maximum value exceeding $600 \mathrm{~km} / \mathrm{s}$ on 27 August, and the $K p$ reached 5 around 15:00 UTC on 27 August, indicating that a moderate disturbance still remained in the early stage of the storm recovery phase. Afterward, the gradually recovering $S Y H-H$ index during the 27-30 August indicated quiet geomagnetic conditions at the later storm recovery phase.

\section{TEC observations from the ground-based GNSS network}

For showing the ionospheric perturbation during magnetic storms, the quiet-time background needs to be first determined. For both storms, quiet days are selected from the month in September 2017 and August 2018 separately, and only the days with minimum SYM- $H$ index of the day not lower than $-25 \mathrm{nT}$ and maximum value not exceeding $10 \mathrm{nT}$ are considered. The TEC values in the quiet days are first assigned to their magnetic coordinates and then sorted into bins of $2^{\circ} \times 5^{\circ}$ (MLAT versus geographic longitude) with a time cadence of $15 \mathrm{~min}$. The mean value in each bin is then taken as the quiet-time reference. In storm periods, the TEC values are sorted into the same bins and then subtract the quiet-time reference to get the TEC perturbation $(\triangle \mathrm{TEC})$.

To focus on the equatorial and low latitudes, especially at the Equatorial Ionization Anomaly (EIA) crest region, the $\triangle \mathrm{TEC}$ values within $10^{\circ}$ to $20^{\circ}$ MLAT and $-10^{\circ}$ to $-20^{\circ}$ MLAT is averaged for representing the northern and southern EIA crests, respectively. Figure $2 \mathrm{a}$ and $\mathrm{b}$ present the longitude versus UTC (with a time cadence of $15 \mathrm{~min}$ ) variations of the averaged $\triangle \mathrm{TEC}$ at the two crests during 6-11 September. The gray dashed lines represent local noon at the different longitudes. During the storm main phase on 7-8 September, positive values of $\triangle T E C$ are observed at almost all longitudes on the dayside, but during the storm recovery phase opposite distributions of $\triangle \mathrm{TEC}$ are seen in the eastern and western longitudes, with mainly positive and negative $\triangle \mathrm{TEC}$ in the Asian and 
American sectors, respectively. This feature is consistent for both the northern and southern EIA crests.

For the storm in August 2018, on the dayside, positive $\triangle \mathrm{TEC}$ values are also observed at all longitudes during the storm main phase, roughly from 12:00 UTC of 25 August to 12:00 UTC of 26 August. During the storm recovery phase, the northern EIA crest at the eastern longitudes exhibits mainly positive $\triangle \mathrm{TEC}$, while in the western longitudes negative $\triangle T E C$ was first seen at the early recovery phase (from 12:00 UTC on 26 August to 06:00 UTC on 28 August) and then exhibited as a positive response. The $\triangle T E C$ at the southern EIA crest on the dayside exhibited mainly positive values at almost all longitudes.

As the background TEC and perturbations are larger by an order on the dayside than that on the night side, to have a detailed look at the TEC perturbations on the night side, the results of Fig. 2 are repeated in Fig. 3 with the $\triangle T E C$ values on the dayside (06:00-18:00 LT) in blank, and the range of the color bar limited to \pm 5 TECU. We see that during the storm main and early recovery phases on 7-9 September 2017, nighttime positive $\triangle \mathrm{TEC}$ are observed at most longitudes. During the later stage of the storm recovery phase on 10 and
11 September, at the eastern longitudes the $\triangle$ TECs are mainly positive, but with relative weaker values compared to the prominent TEC enhancement on the dayside; while at the western longitudes, they are mainly negative, which is similar to the daytime response at these longitudes. Note that this longitudinal dependence of the ionospheric perturbation is the same for both the southern and northern hemispheres. For the storm in August 2018, the western longitudes exhibited stronger TEC enhancement compared to the eastern hemisphere during the storm main phase (on 26 August), but then it reversed with larger $\triangle \mathrm{TEC}$ values in the eastern longitudes (from 18:00 UTC of 26 August to the beginning of 27 August). This longitudinal variation of $\triangle T E C$ agrees well with the explanation that the geomagnetic storm surges tend to develop firstly in the longitudes which are in the night side (Prölss, 1993). During the recovery phase on 27-29 August, the $\triangle T E C$ at the northern EIA crest were mainly positive in the eastern longitudes but slightly negative in the western longitudes, while the $\triangle \mathrm{TEC}$ at the southern EIA crest were positive at most of the longitudes, implying a north-south asymmetry of the EIA crests.


Fig. 3 As the same format as that in Fig. 2, but the $\triangle T E C$ at daytime (06:00-18:00 LT) is set as blank to emphasize the nighttime $\triangle T E C$ distributions 


\section{In-situ observations of small-scale plasma irregularities} from Swarm satellites

To show the global occurrence of small-scale plasma irregularities, we recorded the latitude (both geographic and magnetic) and longitude of EPIs identified from each orbit of the three Swarm satellites. Figure 4 presents the geographic longitude (a and c panels) and magnetic latitude ( $b$ and $d$ panels) versus UTC distributions of the small-scale EPIs during the two geomagnetic storms. For the storm in September 2017, the irregularities were rather evenly distributed at all the longitudes during the storm main phase (on 6-8 September, Fig. 4a). The enhanced EPIs (extending from the magnetic equator to middle latitudes, Fig. 4b) witnessed in the AtlanticAmerican sector on 8 September should be the main causes of the ionospheric scintillation as reported by Mrak et al. (2020). However, in the storm recovery phase on 9-10 September, the irregularities are dismissed in the Atlantic-American sector (from $-90^{\circ}$ to $0^{\circ} \mathrm{E}$ ). A similar phenomenon can also be captured during the August 2018 storm, that is, the irregularities are dismissed in the longitudinal sector of from $-120^{\circ}$ to $120^{\circ}$ on $27-28$ August (Fig. 4c).

The irregularities also showed interesting occurrence patterns on their latitudinal extension. In both events (Fig. 4b, d ), the irregularities were generally confined at the low and equatorial latitudes before the storm onset, i.e. on 6-7 September 2017 and 24-25 August 2018; afterward, clear latitudinal expansions to the middle latitudes were provoked for the irregularities during the storm main phase (on 8 September 2017 and 26 August 2018); and later during the storm recovery phase on 9-11 September 2017 and 27-29 August 2018, the latitudinal expansion of EPIs disappeared and they have again resided at the low and equatorial latitudes. In the eastern Asian sector, unique severe EPIs events occurred as depleted plasma density structures that extend northeastward from low latitudes to mid-latitudes on 8 September 2017 were confirmed in the Swarm in-situ $\mathrm{Ne}$ measurements as reported by Aa et al. (2018). In addition, in the American sector, the midlatitude irregularities that resided near the Storm Enhanced Density (SED)
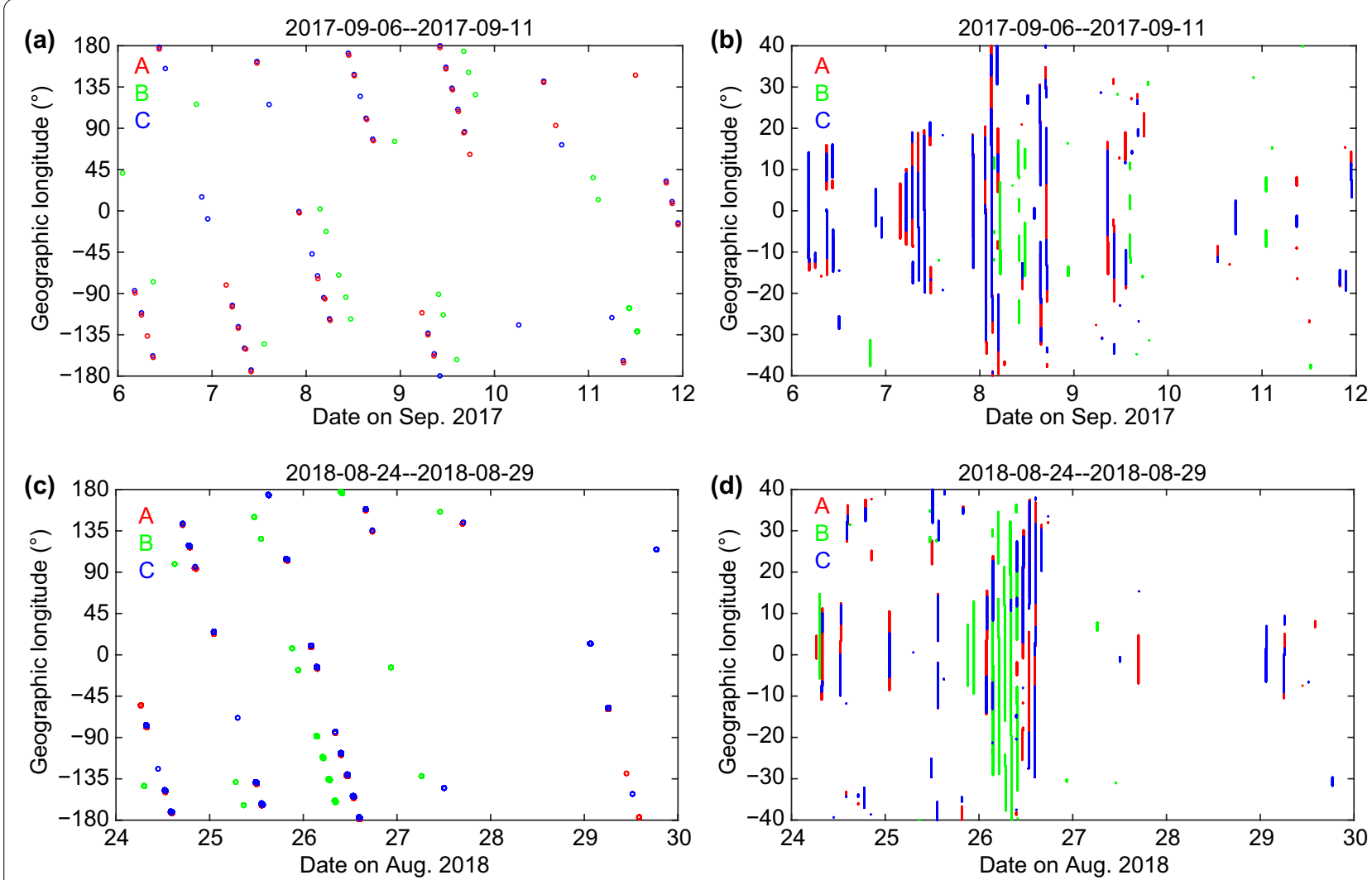

Fig. 4 (a and $\mathbf{c}$ ) The geographic longitude versus UTC and (b and d) MLAT versus UTC distributions of small-scale plasma irregularities observed by the Swarm satellites during geomagnetic storms on (a and b) 6-11 September 2017 and (c and d) 24-29 August 2018. The results from Swarm A, $\mathrm{B}$, and $\mathrm{C}$ are marked with red, green, and blue colors. For the left side panels, each circle represents one equatorial orbital segment of Swarm with small-scale (less than $300 \mathrm{~km}$ ) plasma irregularities detected 
base and ionosphere main trough were also reported to be generated via the gradient drift instability (Nishimura et al., 2021); however, this kind of plasma irregularities are mainly located close to the subaurora region, and they are not the same as the low-latitude EPIs as addressed in our study. Even though, the mechanism of such subauroral plasma irregularities during a storm and the question whether these irregularities are related to the expansion of EPIs from low latitudes are still of interest, which require further study.

\section{TEC and small-scale TEC perturbations from the BeiDou GEO observations}

Because the MIT TEC product is derived from the multiple-GNSS observations and provided in uniform geospatial grids, its spatial resolution is inherently fixed which is not favorable to resolve the small-scale ionospheric structures. To capture the reliable TEC perturbation with small-scale ionospheric irregularities involved, we also used the BeiDou GEO TEC data collected at SHEZ station (geographic latitude/longitude $26.89^{\circ} / 114.46^{\circ} \mathrm{E}$, $20.20^{\circ} \mathrm{MLAT}$ ). Figure 5 shows the TEC variations (red lines) derived from four Beidou GEO satellites (C01C04). The same criteria as used in subsection 3.2 is applied for selecting the magnetic quiet days, and the quiet-day TEC references for each GEO satellite are plotted in black lines.

During the September 2017 storm, a prevailing phenomenon was the strong daytime TEC enhancement witnessed at SHEZ station throughout the main and the recovery phase, which is similar to the TEC observations provided by MIT. The nighttime TEC also showed significant enhancement during the main phase. However, as the storm progressed into the recovery phase, the enhancement kept at a relatively low level or even stayed the same as that of the quiet time level, especially for the TEC values from C02 satellite. During the August 2018 storm, the daytime TEC enhancement was only witnessed in the storm main phase on 26 August. The daytime TEC during the latter recovery phase was even lower than the quiet time reference on 27-29 August 2018. For the nighttime (18:00-06:00 LT, indicated by the grey shadows), slight TEC enhancements were observed also during the storm main phase but kept the same as the quiet-time reference during the storm recovery phase.

The $30 \mathrm{~s}$ resolution of BeiDou GEO TEC data allows us to monitor the small-scale ionospheric irregularities. Different from the previous studies that used the Rate of TEC (ROT), or the Rate of TEC Index (ROTI) over a defined time interval, here we applied a high-pass filter with a cut-off period of $50 \mathrm{~min}$ to the TEC time series. As already explained in Subsection 2.2, by applying this high-pass filter we can focus on the TEC variations with a wavelength less than $300 \mathrm{~km}$ (assuming the zonal drift velocity of irregularities of about $100 \mathrm{~m} / \mathrm{s}$ ), which is also consistent with the small-scale EPIs derived from the Swarm in-situ $\mathrm{Ne}$ measurements. Figure 6 shows the corresponding high-pass filtered TEC variations, organized in the same manner as that in Fig. 5 with nighttime (18:00-06:00 LT) indicated by grey shadows. For the storm of September 2017 (Fig. 6a), the small-scale TEC perturbations were persistently witnessed for three consecutive nights which extend from the storm main phase to the recovery phase (from 8 to 11 August). For the storm of August 2018, the ionosphere seems to be calm with only very weak TEC perturbations observed in the storm main phase and on the dayside of 29 August.

\section{Discussion}

The above results present both the large-scale ionospheric responses and 1 the small-scale EPIs during the two major geomagnetic storms in the last solar cycle. The large-scale TEC variations (Figs. 2 and 3) reveal the prominent longitudinal and storm phase dependence of storm-induced ionospheric responses. The mechanisms for causing the different patterns of the ionospheric responses are possibly due to the lower atmospheric forcing (Lei et al., 2018; Li et al., 2020; Xiong et al., 2019). However what kind of lower atmospheric forcing and the detailed mechanism to cause the topside ionospheric responses are out of the scope of this study. We, therefore, concentrate our discussion on the possible links between the large-scale ionospheric perturbations and the occurrence of small-scale EPIs during geomagnetic storms.

One of the important results seen from the MIT TEC data (Figs. 2 and 3) is that the geomagnetic storminduced ionospheric disturbances show both spatial and temporal dependences. During the geomagnetic storm of September 2017, the daytime ionosphere in the eastern hemisphere showed positive storms throughout the main and recovery phases, while the western hemisphere showed strong positive and negative responses in the main and recovery phases, respectively. For the night side (Fig. 3), the eastern hemisphere exhibited mainly a slightly positive response, while the western hemisphere exhibited a prominent negative response. As is known that the longitudinal asymmetry of ionospheric responses to the geomagnetic storm main phase is usually associated with the UTC effect of the storm onsets. Under the presence of Prereversal Enhancements (PRE) around sunset, the storm-time dynamic associated with PPEF is mostly effective in the dusk sector (e.g., Fejer et al., 2008). As the onset of the two geomagnetic storms occurred shortly before 00:00 UTC 

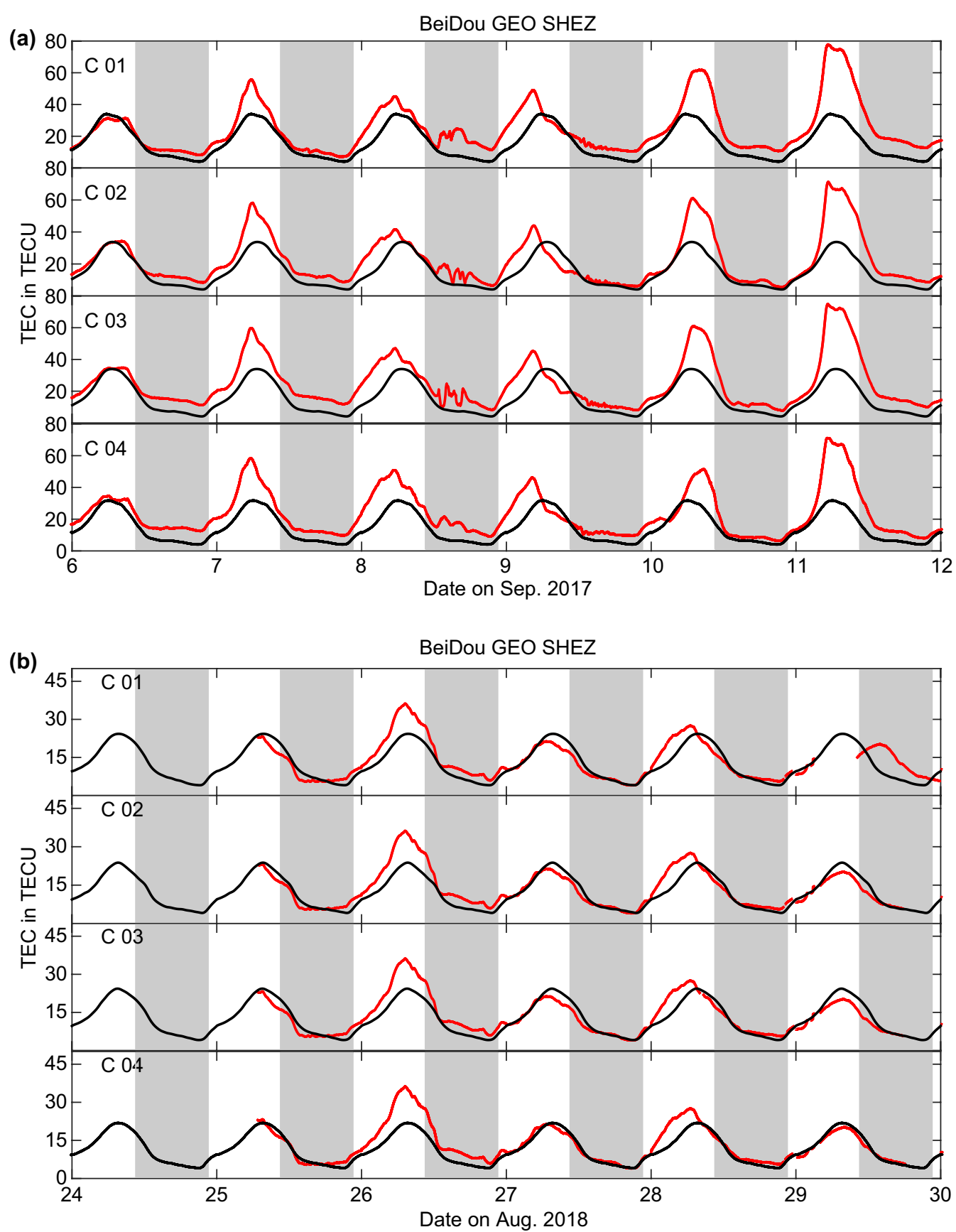

Fig. 5 The BeiDou GEO (C01-04) derived TEC (red) at the station SHEZ during geomagnetic storms on a 6-11 September 2017 and b 24-29 August 2018. The quiet-time references are represented in black lines. The grey shadow area represents the night side between 18:00-06:00 LT

when the American sector is around sunset hours, therefore the prominent positive ionospheric responses were seen at American sector during the main phase of two geomagnetic storms; for the Asian sector (assuming at $120^{\circ} \mathrm{E}$ ) the 00:00 UTC corresponds to local morning hours, and the PPEF is also mainly eastward at this local time, therefore positive ionospheric responses were also observed at the Asian sector during the two storm main phases. However, during the storm recovery phase, the PPEF effect is weak and the DDEF is mainly westward on the dayside, so that the ionospheric plasma moves to lower altitudes where the recombination rate is high, and thus its density is reduced. Therefore, the longlasting daytime enhancements in the Asian sector, as 

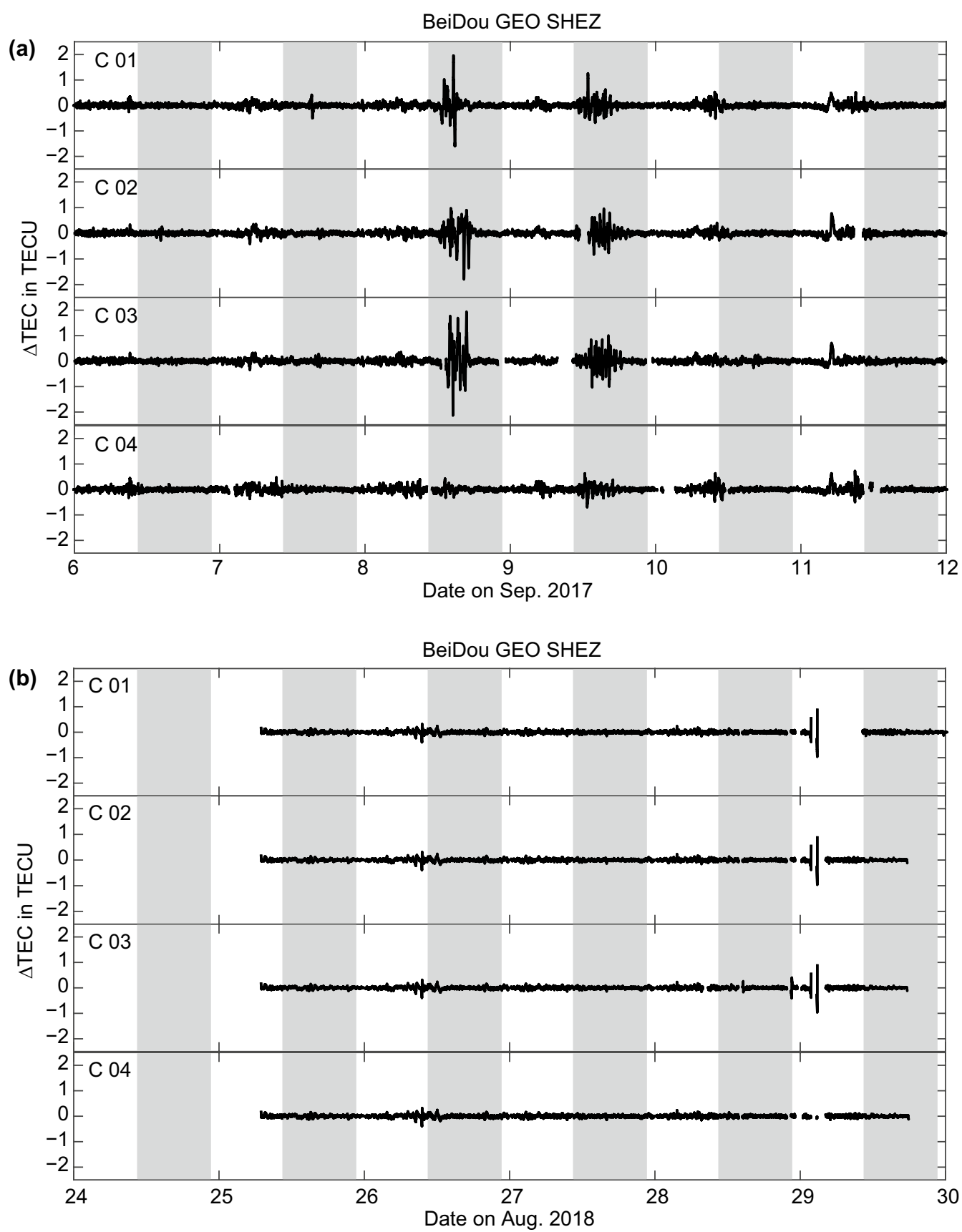

Fig. 6 As the same format as that in Fig. 5, but for showing the activity of small-scale TEC perturbations (less than $300 \mathrm{~km}$ )

reported by Lei et al. (2018) and Xiong et al. (2019) cannot be well explained by the PPEF or DDEF related processes. The further observations of enhanced $\mathrm{E}$ region electric fields and EEJ provided by the two studies supported the concept that the lower atmospheric forcing is involved during such a storm recovery phase.

One question raised here is if the daytime ionosphere response can prolong to the night side during the storm recovery phase. When compared with the distribution of the nighttime F-region irregularities seen by the Swarm constellation (Fig. 4a), we found that the nighttime small-scale irregularities were dismissed in the Africa-Atlantic-American sector where the strong negative ionospheric storm prevailed in both the daytime and nighttime; while for the longitude sector of western Pacific and Asian regions, the nighttime TEC is slightly 
increased and enhanced small-scale EPIs were also observed. From these results, it seems the nighttime ionospheric responses (including the small-scale plasma irregularities) share the same longitudinal dependence as the dayside ionospheric responses, though it challenges our current understanding that the DDEF usually causes negative/positive ionospheric perturbations on the day/ night sides (e.g., Blanc \& Richmond, 1980; Scherliess \& Fejer, 1997). But as already argued above, if the TEC enhancements in the storm recovery phase reported by Lei et al. (2018) and Xiong et al. (2019) are indeed related to the lower atmospheric tides and wave forcing (with role overcomes that of DDEF), their influences on the topside ionosphere can also be prolonged to the nighttime, as shown in Fig. 3.

As for the storm of August 2018, similar relations between the large-scale TEC disturbance and the occurrence of EPIs are also captured. The vacuum of the irregularities from $-120^{\circ}$ to $120^{\circ} \mathrm{E}$ during $27-28$ August is well characterized by strong daytime ionospheric negative storms despite that the nighttime TEC is weakly enhanced. All these suggest that the nighttime ionospheric irregularities have a close relationship with the daytime ionosphere perturbations during the recovery phase of the two geomagnetic storms.

As is known, the thermospheric composition change is one of the important reasons to cause an ionospheric negative storm at the low- and mid-latitudes. However, the opposite ionospheric response in Asian and American sectors during the storm recovery phase on 9-11 September 2017 cannot be well explained by the variation of $\mathrm{O} / \mathrm{N}_{2}$ measured with the Global Ultraviolet Imager (GUVI) onboard Thermosphere Ionosphere Mesosphere Energy and Dynamics (TIMED) satellite, as no opposite $\mathrm{O} / \mathrm{N}_{2}$ variations were observed (Xiong et al., 2019). From this point of view, the opposite daytime ionospheric response in Asian and America sectors during this storm recovery phase is quite different from the statistical behavior of the low latitude ionosphere. In addition to the thermospheric composition change, another mechanism for causing the positive/negative ionospheric storm at the low and equatorial latitudes is the disturbed electric fields that further results in the disturbance of the vertical plasm drift (e.g., Fejer, 1997; Lei et al., 2018; $\mathrm{Li}$ et al., 2020 and references therein). That is, the upward velocity drives the plasma to a higher altitude where the chemical combination rate as well as the plasma density is low and leaves a depleted bottom side ionosphere to promote more ionization (in the daytime), increasing both the topside plasma density and TEC. The downward plasma velocity would cause a negative storm in a similar way. Note that the vertical displacement of the plasma alone will not change the TEC, but it is the changes of the ionization (daytime) and recombination rate and the pressure gradient induced horizontal transportation of plasma. Thus, the TEC might respond almost in real-time to the vertical drifts since the time scale of the ionization/ recombination at ionospheric height is short. Because the development of EPIs is closely related to the RayleighTaylor instability whose growth rate is proportional to the plasma density gradient and the vertical drift velocity (e.g., Sultan, 1996), the enhanced downward plasma drift will cause not only the negative storm but also the inhibited occurrence of EPIs. Thus, it is acceptable that the nighttime irregularities will be dismissed in the region where the negative ionospheric storm occurred throughout the day and night.

However, when the ionosphere has different behaviors during the day and night, the question is why the occurrence of small-scale EPIs is likely to be affected by the daytime ionospheric variations. Under the control of the growth rate of Rayleigh-Taylor instability, the final presentation of irregularities requires a slow generation process which is determined by the background ionosphere around sunset hours when a steep vertical plasma density gradient forms. From Figs. 2 and 3, we see that the large-scale ionospheric responses in sunset hours share the same behavior as their variations on the dayside. As a result, the enhanced/reduced dusk side ionosphere will cause an increase/decrease of the vertical plasma density gradients, which further promotes/inhibits the generation and evolution of the EPIs.

The localized GEO TEC observations at SHEZ station support this scenario. During 8-11 September 2017, the daytime TEC is significantly enhanced while the nighttime TEC stays at the same level or is only slightly enhanced. Meanwhile, the strong small-scale TEC fluctuations in the nighttime agree quite well with the occurrence of F-region EPIs probed by the Swarm satellites in the Asian region. One interesting feature is that in the storm main and earlier recovery phase (on 8-9 September), the small-scale perturbations were much stronger in the night hours than that in the daytime; while during the later recovery phase (on 10-11 September), the perturbations in daytime seem to be stronger but rapidly deceased in the post-sunset hours. This different feature indicated the dayside small-scale TEC perturbations in the later storm recovery phase have different origins rather than the nighttime EPIs. We speculated that such daytime small-scale irregularities might be related to the daytime periodic wave-like structures as reported by Huang et al. (2019), which was attributed to the stratospheric gravity wave activities.

For the storm in August 2018, although Li et al. (2020) found in general a positive ionospheric response in the Asian sector during the storm recovery phase, different 
TEC perturbations were observed for the stations at different latitudes, with a much weaker positive response (or even negative) for the northern stations, e.g., the BBKD and HKWS (see their Fig. 3). This north-south hemispheric asymmetry corresponds well to the $\triangle T E C$ distributions in the northern and southern EIA crests as shown in Fig. 2c and d. As the SHEZ station is located at the poleward of the northern EIA crest, the observed daytime TEC barely exhibited enhancement and the nighttime TEC remained at the same level as the quiettime reference. Correspondingly, no prominent smallscale TEC perturbations were observed during this storm. This result also supports the idea that the prominent north-south asymmetry of EIA around sunset hours will suppress the development of small-scale EPIs (e.g., Abdu, 2019).

\section{Summary}

In this study, we explored both the large-scale ionospheric variations and small-scale EPIs at equatorial and low latitudes in response to the geomagnetic storms which happened on 7-8 September 2017 and 25-26 August 2018. One reason for us to focus on these two storms is that similar long-lasting TEC enhancements in the Asian sector were observed during both storm recovery phases. The main findings are summarized as bellows.

1. During the recovery phase of the September 2017 storm, the nighttime ionosphere in the American sector is largely depressed, which is similar to the daytime ionospheric response in the same longitude sector; while in the Asian sector, only a slight TEC increase is observed at nighttime, which is weaker than the prominent daytime TEC enhancement in this longitude sector.

2. During the recovery phase of the August 2018 storm, slight TEC increases are observed at all longitudes, which is also weaker than the prominent daytime TEC enhancement at all longitudes. Compared to the storm in September 2017, The TEC in both the day and night sides show a clear asymmetry in the northern and southern EIA crest regions.

3. During the main phases of the two storms, the small-scale ionospheric irregularities at nighttime are enhanced and extended to midlatitudes. Different distributions are seen in the storm recovery phases. For the first storm, the small-scale ionospheric irregularities are enhanced only in the Asian sector but are largely depressed in the American sector; for the second storm, no prominent nighttime small-scale irregularities were observed.
4. The nighttime EPIs tend to occur/dismiss in the regions where the daytime ionospheric positive/ negative occurs. We suggest that the dusk side ionospheric response could be affected by the daytime ionospheric plasma density/TEC variations during the recovery phase of geomagnetic storms, which further modulates the vertical plasma drift and plasma gradient. As a result, the growth rate of the post-sunset EPIs will be enhanced or inhibited.

\section{Abbreviations}

CME: Coronal mass ejections; DDEF: Disturbance dynamo electric fields; EEJ: Equatorial electrojet; EIA: Equatorial ionization anomaly; EPI: Equatorial plasma irregularity; ESA: European Space Agency; GEO: Geostationary orbit; GNSS: Global Navigation Satellite System; GSM: Geocentric-solar-magnetospheric; IMF: Interplanetary magnetic field; LT: Local time; MIT: Massachusetts Institute of Technology; PPEF: Prompt penetration electric fields; PRE: Prereversal enhancements; SED: Storm enhanced density; TEC: Total electron content; UTC: Coordinated universal time; WACCM-X: Whole Atmosphere Community Climate Model eXtended; GUVI: Global Ultraviolet Imager; TIMED: Thermosphere lonosphere Mesosphere Energy and Dynamics.

\section{Acknowledgements}

We thank the CEDAR Madrigal database for providing global GNSS TEC data; the BeiDou GEO TEC data are provided by the University of Science and Technology of China; the Swarm Ne data are provided by ESA; the solar wind and geomagnetic indices are provided by the GSFC/SPDF OMNIWeb database.

\section{Authors' contributions}

XW analyzed the Ne data from Swarm. SG and FH processed GNSS TEC data and BeiDou GEO TEC data at SHEZ station. CX lead the discussion on data analysis and the content of the study. XW and CX prepared the manuscript with the help from all the authors. All authors read and approved the final manuscript.

\section{Funding}

Chao Xiong is supported by the National Natural Science Foundation of China (42174191) and the start-up program of Wuhan University (600460020). Xin Wan is supported by the China Postdoctoral Science Foundation (2020M683025). Fan Yin is supported by the National Key Research and Development Program of China (Grants 2018YFC1503501-01). This work is also supported by the Dragon 5 cooperation 2020-2024 (project no. 59236) and Chinese Meridian Project.

\section{Availability of data and materials}

The MIT GNSS TEC data is available at http://cedar.openmadrigal.org/ftp/. The Swarm Ne data are provided by ESA at https://earth.esa.int/web/guest/ swarm/data-access. The solar wind and geomagnetic indices are available at OMNIWeb database https://omniweb.gsfc.nasa.gov/.

\section{Declarations}

Competing interests

The authors declare that they have no competing interests.

\section{Author details}

1Planetary Environmental and Astrobiological Research Laboratory (PEARL), School of Atmospheric Sciences, Sun Yat-Sen University, Zhuhai, China. ${ }^{2}$ Department of Space Physics, Electronic Information School, Wuhan University, Wuhan 430072, China. ${ }^{3}$ Mengcheng National Geophysical Observatory, University of Science and Technology of China, Hefei, China. ${ }^{4}$ Chinese Academy of Sciences Key Laboratory of Geospace Environment, School of Earth and Space Sciences, University of Science and Technology of China, 
Hefei, China. ${ }^{5}$ School of Physics and Electronic Information, Shangrao Normal University, Shangrao, China. ${ }^{6}$ Haystack Observatory, Massachusetts Institute of Technology, Westford, MA, USA.

Received: 7 June 2021 Accepted: 24 September 2021 Published online: 01 November 2021

\section{References}

Aa, E., Huang, W., Liu, S., Ridley, A., Zou, S., Shi, L., et al. (2018). Midlatitude plasma bubbles over China and adjacent areas during a magnetic storm on 8 September 2017. Space Weather, 16, 321-331. https://doi.org/10. 1002/2017SW001776

Abdu, M. A. (2019). Day-to-day and short-term variabilities in the equatorial plasma bubble/spread $\mathrm{F}$ irregularity seeding and development. Progress in Earth and Planetary Science, 6, 11. https://doi.org/10.1186/ s40645-019-0258-1

Astafyeva, E., Zakharenkova, I., \& Doornbos, E. (2015). Opposite hemispheric asymmetries during the ionospheric storm of 29-31 August 2004. Journal of Geophysical Research:Space Physics, 120(1), 697-714. https://doi.org/10. 1002/2014JA020710

Basu, S., \& Basu, S. (1981). Equatorial scintillations-a review. Journal of Atmospheric and Terrestrial Physics, 43, 473-489.

Blanc, M., \& Richmond, A. (1980). The ionospheric disturbance dynamo. Journal of Geophysical Research, 85, 1669-1686. https://doi.org/10.1029/JA085 iA04p01669

Carter, B. A., et al. (2014). Geomagnetic control of equatorial plasma bubble activity modeled by the TIEGCM with Kp. Geophysical Research Letters, 41, 5331-5339. https://doi.org/10.1002/2014GL060953

Coster, A. J., Foster, J. C., \& Erickson, P. J. (2003). Monitoring the ionosphere with GPS. GPS World, 14(5), 42-45.

Emmert, J. T., Richmond, A. D., \& Drob, D. F. (2010). A computationally compact representation of magnetic-apex and quasi-dipole coordinates with smooth base vectors. Journal of Geophysical Research, 115, A08322. https://doi.org/10.1029/2010JA015326

England, S. L., Immel, T. J., Huba, J. D., Hagan, M. E., Maute, A., \& DeMajistre, R. (2010). Modeling of multiple effects of atmospheric tides on the ionosphere: An examination of possible coupling mechanisms responsible for the longitudinal structure of the equatorial ionosphere. Journal of Geophysical Research, 115, A05308. https://doi.org/10.1029/2009JA014894

Fejer, B. G. (1997). The electrodynamics of the low-latitude ionosphere: Recent results and future challenges. Journal of Atmospheric and Terrestrial Physics, 59, 1465-1482. https://doi.org/10.1016/s1364-6826(96)00149-6

Fejer, B. G., Jensen, J. W., \& Su, S.-Y. (2008). Seasonal and longitudinal dependence of equatorial disturbance vertical plasma drifts. Geophysical Research Letters, 35, L20106. https://doi.org/10.1029/2008GL03558

Fuller-Rowell, T.J., Codrescu, M.V., Roble, R.G. and Richmond, A.D. (1997). How Does the Thermosphere and Ionosphere React to a Geomagnetic Storm? In B.T. Tsurutani, W.D. Gonzalez, Y. Kamide and J.K. Arballo (eds) Magnetic Storms. https://doi.org/10.1029/GM098p0203

Goncharenko, L. P., Foster, J., Coster, A., Huang, C., Aponte, N., \& Paxton, L. (2007). Observations of a positive storm phase on September 10, 2005. Journal of Atmospheric and Solar-Terrestrial Physics, 69(10-11), 1253-1272. https://doi.org/10.1016/j.jastp.2006.09.011

Hagan, M. E., Maute, A., \& Roble, R. G. (2009). Tropospheric tidal effects on the middle and upper atmosphere. Journal of Geophysical Research, 114, A01302. https://doi.org/10.1029/2008JA013637

Häusler, K., \& Lühr, H. (2009). Nonmigrating tidal signals in the upper thermospheric zonal wind at equatorial latitudes as observed by CHAMP. Annales Geophysicae, 27(7), 2643-2652.

Huang, F., Lei, J., \& Dou, X. (2017). Daytime ionospheric longitudinal gradients seen in the observations from a regional BeiDou GEO receiver network. Journal of Geophysical Research: Space Physics, 122, 6552-6561. https://doi. org/10.1002/2017JA023881

Huang, F., Lei, J., Dou, X., Luan, X., \& Zhong, J. (2018). Nighttime mediumscale traveling ionospheric disturbances from airglow imager and Global Navigation Satellite Systems observations. Geophysical Research Letters, 45 , 31-38. https://doi.org/10.1002/2017GL076408

Huang, F., Otsuka, Y., Lei, J., Luan, X., Dou, X., \& Li, G. (2019). Daytime periodic wave-like structures in the ionosphere observed at low latitudes over the Asian-Australian sector using total electron content from Beidou geostationary satellites. Journal of Geophysical Research: Space Physics, 124 2312-2322. https://doi.org/10.1029/2018JA026443

Hocke, K., \& Schlegel, K. (1996). A review of atmospheric gravity waves and traveling ionospheric disturbances: 1982-1995. Annales De Geophysique 14(9), 917-940. https://doi.org/10.1007/s00585-996-0917-6

Immel, T. J., Sagawa, E., England, S. L., Henderson, S. B., Hagan, M. E., Mende, S. B., Frey, H. U., Swenson, C. M., \& Paxton, L. J. (2006). Control of equatorial ionospheric morphology by atmospheric tides. Geophysical Research Letters, 33, L15108. https://doi.org/10.1029/2006GL026161

Kikuchi, T., Lühr, H., Kitamura, T., Saka, O., \& Schlegel, K. (1996). Direct penetration of the polar electric field to the equator during a DP 2 event as detected by the auroral and equatorial magnetometer chains and the EISCAT radar. Journal of Geophysical Research, 101(A8), 17161-17173. https://doi.org/10.1029/96JA01299

Kintner, P. M., Kil, H., Beach, T. L., \& de Paula, E. R. (2001). Fading timescales associated with GPS signal and potential consequences. Radio Science, 36(4), 731-743. https://doi.org/10.1109/1999RS002310

Lei, J., Huang, F., Chen, X., Zhong, J., Ren, D., Wang, W., Yue, X., Luan, X., Jia, M., Dou, X., Hu, L., Ning, B., Owolabi, C., Chen, J., Li, G., \& Xue, X. (2018). Was magnetic storm the only driver of the long-duration enhancements of daytime total electron content in the Asian-Australian sector between 7 and 12 September 2017? Journal of Geophysical Research:Space Physics, 123, 3217-3232. https://doi.org/10.1029/2017JA025166

Li, Q., Huang, F., Zhong, J., Zhang, R., Kuai, J., Lei, J., et al. (2020). Persistence of the long-duration daytime TEC enhancements at different longitudinal sectors during the August 2018 geomagnetic storm. Journal of Geophysical Research: Space Physics, 125, e2020JA028238. https://doi.org/10. 1029/2020JA028238

Mrak, S., Semeter, J., Nishimura, Y., Rodrigues, F. S., Coster, A. J., \& Groves, K. (2020). Leveraging geodetic GPS receivers for ionospheric scintillation science. Radio Science, 55, e2020RS007131. https://doi.org/10.1029/ 2020RS007131

Nishida, A. (1968). Coherence of geomagnetic DP 2 fluctuations with interplanetary magnetic variations. Journal of Geophysical Research, 73(17), 5549-5559. https://doi.org/10.1029/JA073i017p05549

Nishimura, Y., Mrak, S., Semeter, J. L., Coster, A. J., Jayachandran, P. T., Groves, K. M., et al. (2021). Evolution of mid-latitude density irregularities and scintillation in North America during the 7-8 September 2017 storm. Journal of Geophysical Research: Space Physics, 126, e2021JA029192. https://doi. org/10.1029/2021JA029192

Pedatella, N. M. (2016). Impact of the lower atmosphere on the ionosphere response to a geomagnetic superstorm. Geophysical Research Letters, 43, 9383-9389. https://doi.org/10.1002/2016GL070592

Pedatella, N. M., \& Liu, H.-L. (2018). The influence of internal atmospheric variability on the ionosphere response to a geomagnetic storm. Geophysical Research Letters, 45, 4578-4585. https://doi.org/10.1029/2018GL077867

Prölss, G. W. (1993). On explaining the local time variation of ionospheric storm effects. Annales Geophysicae, 11, 19.

Prölss, G. W. (1995). lonospheric F-region storms. In H. Volland (Ed.), Handbook of atmospheric electrodynamics (Vol. 2, pp. 195-248). CRC Press.

Redmon R, Seaton D, Steenburgh R, He J, Rodriguez J (2018) 2017's geoeffective space weather and impacts to Caribbean radio communications during hurricane response, Earth and Space Science Open Archive. https:// doi.org/10.1002/essoar.a530e85443c2d357.102532a29f074aec.2

Richmond, A. D., \& Matsushita, S. (1975). Thermospheric response to a magnetic substorm. Journal of Geophysical Research, 80(19), 2839-2850. https://doi.org/10.1029/JA080i019p02839

Scherliess, L., \& Fejer, B. G. (1997). Storm time dependence of equatorial disturbance dynamo zonal electric fields. Journal of Geophysical Research, 102(A11), 24037-24046. https://doi.org/10.1029/97JA02165

Scherliess, L., Thompson, D. C., \& Schunk, R. W. (2008). Longitudinal variability of low-latitude total electron content: Tidal influences. Journal of Geophysical Research, 113, A01311. https://doi.org/10.1029/2007JA012480

Sultan, P. J. (1996). Linear theory and modeling of the Rayleigh-Taylor instability leading to the occurrence of equatorial spread F. Journal of Geophysical Research, 101, 26875-26891. https://doi.org/10.1029/96JA00682

Wan, W., Xiong, J., Ren, Z., Liu, L., Zhang, M.-L., Ding, F., Ning, B., Zhao, B., \& Yue, X. (2010). Correlation between the ionospheric WN4 signature and the upper atmospheric DE3 tide. Journal of Geophysical Research, 115, A11303. https://doi.org/10.1029/2010JA015527 
Wan, X., Xiong, C., Wang, H., Zhang, K., Zheng, Z., He, Y., \& Yu, L. (2019). A statistical study on the climatology of the equatorial plasma depletions occurrence at topside ionosphere during geomagnetic disturbed periods. Journal of Geophysical Research: Space Physics, 124(10), 8023-8038. https:// doi.org/10.1029/2019JA026926

Xiong, C., Park, J., Lühr, H., Stolle, C., \& Ma, S. Y. (2010). Comparing plasma bubble occurrence rates at CHAMP and GRACE altitudes during high and low solar activity. Annales Geophysicae, 28(9), 1647-1658. https://doi.org/10. 5194/angeo-28-1647-2010

Xiong, C., Luhr, H., \& Fejer, B. G. (2015). Global features of the disturbance winds during storm time deduced from CHAMP observations. Journal of Geophysical Research:Space Physics, 120, 5137-5150. https://doi.org/10. 1002/2015JA021302

Xiong, C., Stolle, C., \& Lühr, H. (2016). The Swarm satellite loss of GPS signal and its relation to ionospheric plasma irregularities. Space Weather, 14, 563-577. https://doi.org/10.1002/2016SW001439
Xiong, C., Stolle, C., \& Park, J. (2018). Climatology of GPS signal loss observed by Swarm satellites. Annales Geophysicae, 36(2), 679-693. https://doi.org/10. 5194/angeo-36-679-2018

Xiong, C., Lühr, H., \& Yamazaki, Y. (2019). An opposite response of the lowlatitude ionosphere at Asian and American sectors during storm recovery phases: Drivers from below or above. Journal of Geophysical Research: Space Physics, 124, 6266-6280. https://doi.org/10.1029/2019JA026917

Yao, D., \& Makela, J. J. (2007). Analysis of equatorial plasma bubble zonal drift velocities in the Pacific sector by imaging techniques. Annales Geophysicae, 25, 701-709. https://doi.org/10.5194/angeo-25-701-2007

\section{Publisher's Note}

Springer Nature remains neutral with regard to jurisdictional claims in published maps and institutional affiliations.

\section{Submit your manuscript to a SpringerOpen ${ }^{\circ}$ journal and benefit from:}

- Convenient online submission

- Rigorous peer review

- Open access: articles freely available online

- High visibility within the field

- Retaining the copyright to your article

Submit your next manuscript at $\boldsymbol{\nabla}$ springeropen.com 